\title{
Getting over the shock: taking action on Indigenous maternal smoking
}

\author{
Gillian S. Gould ${ }^{\mathrm{A}, \mathrm{D}}$, Yvonne Cadet-James ${ }^{\mathrm{B}}$ and Alan R. Clough \\ ${ }^{A}$ Centre for Brain and Mental Health, School of Medicine and Public Health, University of Newcastle, \\ Callaghan, NSW 2308, Australia. \\ ${ }^{B}$ Australian Aboriginal and Torres Strait Islander Centre, James Cook University, Townsville, Qld 4811, Australia. \\ ${ }^{\mathrm{C}}$ Australian Institute of Tropical Health and Medicine, James Cook University, Cairns, Qld 4870, Australia. \\ DCorresponding author. Email: gillian.gould@newcastle.edu.au
}

\begin{abstract}
Smoking rates are slow to decline among pregnant Indigenous women. One in two pregnant Indigenous Australian women is a tobacco smoker compared with one in eight in the non-Indigenous population. The National Close the Gap strategy ambitiously aims to reduce Indigenous smoking prevalence to half by 2018, but this goal is unlikely to be achieved. Evidence is growing to better inform targeted strategies for Indigenous pregnant women based on national and international studies. It is proposed to be an appropriate time to refine translational approaches for anti-tobacco messages and cessation support in this population, rather than waiting for further empirical research before making these essential changes. Systemic barriers to Indigenous pregnant women receiving equitable primary health care have been identified, are remediable, and urgently require addressing. These barriers include: (1) lack of subsidised access to suitable oral forms of nicotine replacement therapy; (2) lack of clinician training in the complex area of management of maternal Indigenous smoking; and (3) lack of targeted health promotion programs addressing the psychosocial challenges that Indigenous women face. In the interim, translational strategies to target tobacco control and cessation in pregnant Indigenous women need to be based on current evidence.
\end{abstract}

Received 10 March 2015, accepted 21 February 2016, published online 21 July 2016

\section{Introduction}

Indigenous smoking rates must reduce at six-fold the current decline rate to achieve the 2018 Close the Gap target (Thomas 2012). Among Indigenous women in the 25- to 34-year age range, and smokers living in remote locations, rates have remained unchanged for the last decade (Australian Bureau of Statistics 2014). Recently, the Cancer Council Queensland expressed 'shock over Indigenous pregnancy smoking rates', with 53\% of Indigenous pregnant women smoking $v .15 \%$ of their nonIndigenous counterparts (Cancer Council Queensland 2014). Similarly in NSW, 50\% of Indigenous women smoke compared with $9 \%$ of their non-Indigenous counterparts, with a three to five-fold increase in relative risk since 1996 (NSW Department of Health 2014).

Tobacco smoking during pregnancy is the most important preventable risk factor for maternal and infant health and is linked with growth restriction, miscarriage and preterm birth (Li et al. 2012). Some 7000 Indigenous babies per annum are exposed in utero to smoking (Li et al. 2012). Indigenous babies are twice as likely to be of low birthweight, yet if during the first 4 months of pregnancy the mother stops smoking, the low birthweight risk decreases to non-smoking levels (Li et al. 2012).

In light of these patterns and trends, and the benefits for smoking cessation to Indigenous health generally, this article summarises recent evidence, from the body of our work and others, and vigorously debates the following pertinent questions:

(1) Are anti-tobacco messages having an effect on Indigenous pregnant women?

(2) What evidence-based cessation strategies are recommended in pregnancy and how can Indigenous pregnant smokers be encouraged to use them?

(3) What are the systemic barriers for Indigenous pregnant women accessing evidence-based cessation methods, and how can these be addressed?

With these three questions, we take an integrated view of primary healthcare approaches. Health promotion messages are included in our deliberations; these are not just the domain of media campaigns, but are important for everyday communication. The Primary Health Care Research and Information Service website includes in their definition of primary health care (PHC): 'In Australia, PHC incorporates personal care with health promotion, the prevention of illness and community development.' Understanding the responses of pregnant Indigenous women in this area is important for primary care. We draw inferences from the Behaviour Change Wheel (BCW), a parsimonious model developed from an overarching synthesis of behaviour intervention frameworks, and use it to structure our discussions about how strategies for 


\section{What is known about the topic?}

- National smoking rates are high among Indigenous pregnant women, are slow to decline, and few Indigenous women are able to quit unaided during pregnancy.

\section{What does this paper add?}

- Building on available evidence and the framework of the Behaviour Change Wheel, it is proposed that urgent remediation of the significant barriers to providing best practice translational approaches in primary health care is required to better support Indigenous women to quit smoking.

this population can be strengthened (Fig. 1) (Michie et al. 2011). The BCW has been used previously to review the barriers and enablers for smoking cessation in this target group (Gould 2014). This paper addresses recent research to determine how the $\mathrm{BCW}$ can be practically applied. The outer circle of the $\mathrm{BCW}$ comprises a policy layer, the inner circle represents the individual's behaviour and the middle circle an interventional layer that connects the inner and the outer layers.

\section{Effect of anti-tobacco messages on Indigenous pregnant women}

Tobacco campaigns operate on the outer circle or policy layer of the $\mathrm{BCW}$ (communication and marketing) and influence multiple points on the middle interventional layer by persuasion, education, enablement, coercion and modelling. In turn, these interventions centrally influence the individual's capability (C), opportunity (O) and motivation (M) for change - the authors of the model propose that all three $\mathrm{C}-\mathrm{O}-\mathrm{M}$ are required to change behaviour (B) - otherwise known as the COM-B approach (Michie et al. 2011).

Table 1 chronologically summarises tobacco campaigns directed towards Indigenous Australians. Indigenous-targeted national campaigns achieve limited media exposure compared with campaigns aimed at the general Australian population. Many local Tackling Indigenous Smoking campaigns are operating out of primary health centres such as Aboriginal Health Services, both community-controlled and governmentrun; $55 \%$ are targeting pregnant women. Funding to this program has been substantially cut before the outcomes have been assessed.

Indigenous Australians prefer culturally targeted messages (Gould et al. 2013a). A national survey of 47 organisations, including primary health services, reported that community responses to messages targeting Indigenous Australians positively exceeded the organisations' expectations (Gould et al. 2014). Indigenous Australian smokers demonstrated good recall of anti-tobacco messages (Gould et al. 2013a; Nicholson et al. 2015a) and these messages were associated with intentions to quit smoking (Nicholson et al. 2015b). This may be mediated by increased perceptions of the threat from smoking and reflective motivation (Nicholson et al. 2015a). However, messages in isolation may not provide the opportunity, nor improve the

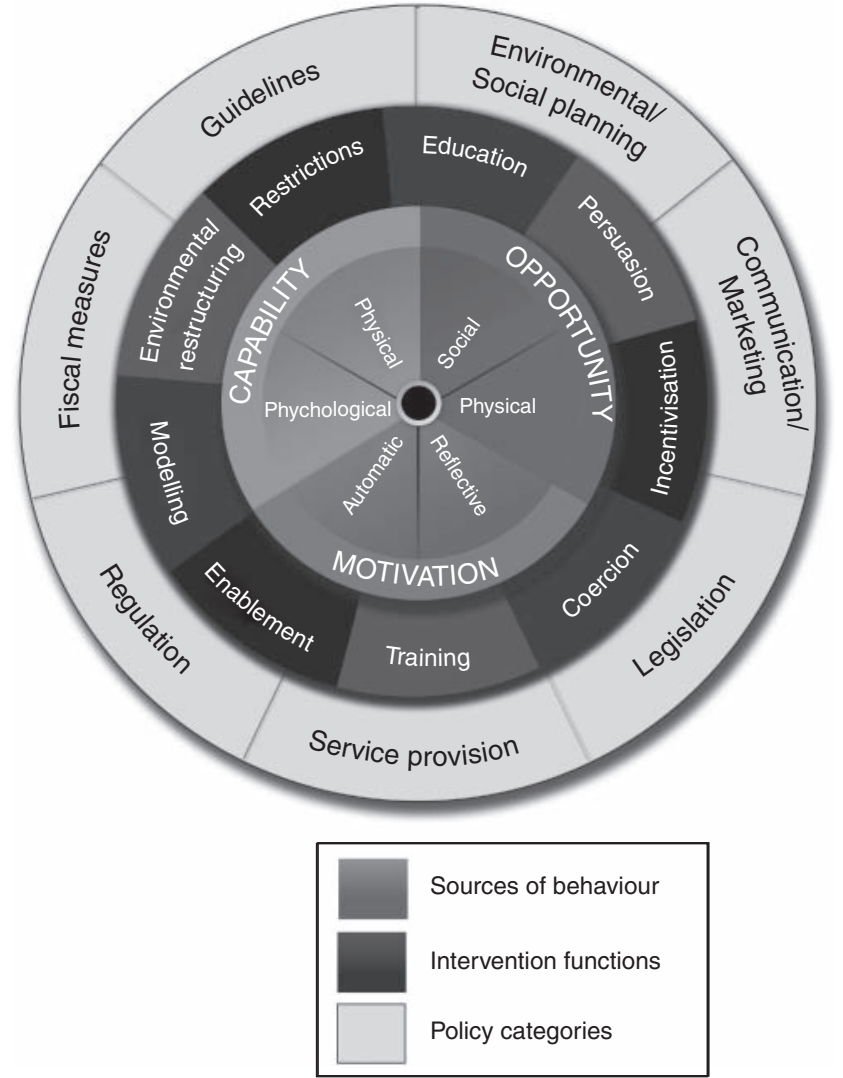

Fig. 1. Behaviour Change Wheel (reproduced with permission from Michie et al. 2011).

capability of Indigenous smokers to quit, thus they should be supported by primary healthcare approaches.

Australian Indigenous pregnant women may encounter psychosocial challenges related to their use of tobacco. These include the historical aspects of smoking and colonisation, the social norms of smoking in some Indigenous communities, the stressors associated with everyday life and the added concern of using an addictive substance (Gould et al. 2013b). In pregnancy, women perceive their smoking risks and their role differently, thus pregnancy can be considered a 'teachable moment' for smoking cessation (McBride et al. 2003). In this case, motivation, as per the $\mathrm{BCW}$, is an automatic or instinctive activity, but can lead to reflective evaluations and plans. When Indigenous women recognise the presence of adverse outcomes in their own or others' children through their smoking, they may express shame and guilt. The stigma of smoking with a 'big belly' has been reported (Gould et al. $2013 b, 2013 c$ ). Messages about smoking in pregnancy are salient in these instances.

Conversely, anti-tobacco messages can lack salience in pregnancy (Gould et al. 2013b, 2013c). A mismatch in prevailing messages and women's lived experiences of smoking can affect women's psychological capability and motivation to take action. For example, there can be a lack of visibility of harm for babies, if other family members have smoked without obvious adverse outcomes. Anti-tobacco 
Table 1. Timeline of anti-tobacco message development for Indigenous Australians AMA, Australian Medical Association

\begin{tabular}{|c|c|c|}
\hline Dates & Campaign or Project & Target and evidence (where available) \\
\hline 1999 & National Tobacco Campaign evaluation (Murphy and Mee 1999). & Indigenous viewers prefer targeted and local campaigns. \\
\hline 2000 & AMA report on the 'Forgotten Smokers' (Market Equity 2000). & $\begin{array}{l}\text { Recommends Indigenous tobacco control messages and targeted } \\
\text { cessation. }\end{array}$ \\
\hline 2006 & $\begin{array}{l}\text { 'Make Smoking History' TV campaign and radio adverts by } \\
\text { Aboriginal comedian 'Mary G' WA. }\end{array}$ & $\begin{array}{l}\text { Aboriginal families promote smoke-free cars. Smoking in cars by } \\
\text { Indigenous smokers drops from } 50 \text { to } \sim 38 \% \text {. }\end{array}$ \\
\hline 2008 & 'Beyond The Big Smoke' WA. & $\begin{array}{l}\text { Targeted tobacco control for Indigenous smokers through Aboriginal } \\
\text { Community Controlled Health Services. }\end{array}$ \\
\hline $2008-2010$ & Indigenous Tobacco Control Initiative. & $\begin{array}{l}\text { Six targeted projects in } 2008-2009 \text {, followed by } 14 \text { projects } \\
\text { nationally in } 2010 \text {. }\end{array}$ \\
\hline 2010 & $\begin{array}{l}\text { 'Break The Chain’ National Tobacco Campaign (Australian } \\
\text { Government 2011). }\end{array}$ & $\begin{array}{l}\text { Indigenous Australians aged } 16-40 \text { years. Unprompted recall } 19 \% \text {; } \\
\text { prompted recall } 77 \% \text { by Indigenous respondents; }>80 \% \text { identified } \\
\text { highly with the advert, whereas a generic campaign, evaluated } \\
\text { by the same respondents, did not elicit the same level of self- } \\
\text { identification; }>50 \% \text { planning to reduce or quit in the next month. }\end{array}$ \\
\hline 2012 & $\begin{array}{l}\text { Tackling Indigenous Smoking and Promoting Healthy Lifestyles } \\
\text { program. }\end{array}$ & $\begin{array}{l}\text { National program in over } 57 \text { regions in Australia include local social } \\
\text { marketing and mass media approaches. Evaluation underway. }\end{array}$ \\
\hline 2012 & $\begin{array}{l}\text { 'Quit for You Quit for Two’ campaign ‘More Targeted Approach’ } \\
\text { (Australian Government 2012). }\end{array}$ & $\begin{array}{l}\text { Pregnant smokers aged } 16-30 \text { years and women planning to } \\
\text { become pregnant. Second wave: unprompted recall }<10 \% \text {; } \\
\text { prompted recall in females who had been pregnant or contemplating } \\
\text { pregnancy } 61 \% ; \sim 75 \% \text { smokers intended to take further action; } \\
40 \% \text { considered quitting. Advertisements considered easy to } \\
\text { understand, believable and thought provoking. }\end{array}$ \\
\hline 2014 & $\begin{array}{l}\text { Organisational survey of Indigenous anti-tobacco message } \\
\text { development (Gould et al. 2014). }\end{array}$ & $\begin{array}{l}\text { In total } 64 \% \text { of } 47 \text { organisations target Indigenous youth; } 55 \% \\
\text { target Indigenous pregnant women. Almost } 50 \% \text { of these } \\
\text { organisations are in Aboriginal primary care. }\end{array}$ \\
\hline
\end{tabular}

messages can be experienced as too confronting when a woman is pregnant, thus the woman may avoid TV advertisements by leaving the room, or deny their relevance (Gould et al. 2013b, 2013c).

\section{Intentions for behaviour change in pregnancy}

Some pregnant Indigenous smokers want to cut down or quit smoking (Gould et al. 2013b, 2013c). Reduced consumption is usual and although quit attempts are made, they have seldom been reported as successful. This may be due to women having a lack of opportunities for advice and assistance with cessation. Others regard cessation as 'too hard' in pregnancy (Passey et al. 2012a), and can even experience stronger urges to smoke during pregnancy, thus affecting a woman's physical capability of cessation (Gould et al. 2013c). A lack of family and partner support can impair a pregnant woman's intention and confidence to quit, and reduce capability, opportunity and motivation. Social norms of smoking, smoking for cohesion and peer bonding, the stressors of everyday life plus lack of self-efficacy (perceived capability) for quitting, can translate into continued tobacco use (Passey et al. 2011, 2012a; Gould et al. 2013b, 2013c). Furthermore, other issues may affect Indigenous women at this time: the pregnancy may be unplanned, women are often in adolescence and urgent social situations have a high priority, such as domestic violence and homelessness. Comprehensive primary care will involve helping women tackle these issues and underlying social determinants of smoking (Gould et al. 2015a). Alternately, pregnant women who do quit are highly regarded as role models by other Indigenous women (Gould et al. 2013c).

Intention to quit by Indigenous smokers can be affected by perceptions of threat and efficacy. A community-based study revealed that a majority $(77 \%)$ of Indigenous smokers of reproductive age perceived smoking to be highly threatening to physical health, implying that reflective motivation is occurring (Gould et al. 2015c). Psychological threats of disgust, regret and stigma about smoking have also been reported (Gould et al. 2015c). Those who consider the threat to lack immediacy, believing 'smoking is not doing me any harm right now', are less motivated to quit (OR 0.25 ; 95\% CI $0.08-0.8$ ) (Gould et al. 2015c). High-perceived efficacy (self-efficacy and response efficacy) for quitting was strongly associated with intention to quit (OR 4.8; 95\% CI 1.78-12.93) (Gould et al. $2015 b$ ), whereas low-perceived efficacy coupled with lowperceived threat (in 16\%) was associated with denial, avoidance or reactance to messages (Gould et al. 2015d). In summary, to raise intentions to quit smoking, careful attention needs to be paid to levels of efficacy (by boosting capability in a real sense), coupled with the level of threat messages Indigenous smokers are exposed to. Approaches to build efficacy for quitting are achievable in primary healthcare settings, through counselling and targeted resources.

Indigenous community members are observing home smoking rules to protect their children and babies (Walker et al. 2015), reflecting on consequences of passive smoking and even challenging each other to achieve these aims (Gould et al. 2013c). However, some may believe only new-born babies are susceptible to environmental tobacco smoke (ETS), thus 
continue to smoke around older children (Gould et al. 2013c). Strategies to avoid third-hand smoke affecting babies and children have been reported in a study involving Australian Indigenous and Maori smokers (Walker et al. 2015), including wearing a smoking shirt and showering. These changes indicate reflective motivation, social and physical opportunities and capacity to restructure the home smoking environment (Gould et al. 2013c).

\section{Considerations for maternal anti-tobacco messages}

Smoking by Indigenous women in pregnancy requires special consideration. Anti-tobacco messages effective in other contexts may sometimes be too confronting in pregnancy, leading to disengagement and self-exempting beliefs, as reported in other pregnant populations (Naughton et al. 2013). The 'Quit for You Quit for Two' campaign with its gentle references to improving pregnancy outcomes may have messages pitched at the right level or tone (Australian Government 2012). However, we believe that messages targeting Indigenous pregnant smokers require expansion in scope to incorporate the evidence emerging from recent studies. Perceptions about susceptibility to smoking harms could be addressed by using the strategies in Table 2, employed at local, regional and national levels, and developed with appropriate Indigenous community consultation. Many of these messages can be delivered in primary healthcare settings to Indigenous pregnant women who smoke, and her family members. These settings are an excellent conduit for targeted materials, and messages can be delivered one-on-one or in small groups.

\section{Evidence-based cessation strategies recommended in pregnancy and how pregnant Indigenous smokers can be encouraged to use them}

National and international guidelines for smoking cessation in pregnancy recommend behavioural counselling, followed by nicotine replacement therapy (NRT) for women unable to quit unaided. NRT is used therapeutically to reduce withdrawal symptoms associated with quitting smoking. It is available as a transdermal patch (slow-acting) and more rapidly acting oral forms such as gum, lozenges, inhaler or a spray. In Australia, oral NRT is the first-line pharmacotherapy in pregnancy, followed by transdermal and then combination NRT (transdermal and oral) if required (Zwar et al. 2014). Effective cessation interventions in pregnancy in the general population include: behaviour change techniques, pregnancy-specific self-help materials, financial incentives, and NRT, often as a combination of a patch and a

Table 2. Suggested responses to beliefs about smoking identified in studies involving pregnant Indigenous women and smokers of reproductive age $\mathrm{CO}$, carbon monoxide; ETS, environmental tobacco smoke; NRT, nicotine replacement therapy

\begin{tabular}{l}
\hline Belief (evidence source) \\
\hline 1. Lack of visibility of harm (Gould et al. 2013b, 2013c) \\
- Smoking is not harmful in pregnancy \\
- No obvious harmful effect from smoking on babies \\
means they are healthy \\
2. Extenuating circumstances for smoking (Passey et al. \\
$2012 a$; Gould et al. $2013 b, 2013 c$ ) \\
- If others smoke around you when you are pregnant, you \\
may as well smoke yourself \\
- It's OK to smoke if you are stressed and smoking is a \\
good way to deal with stress
\end{tabular}

- Smoking in pregnancy keeps birthweight low if you are pre-diabetic

3. Perceptions of harm reduction (Gould et al. 2013b, 2013c)

- Cutting down smoking in pregnancy is sufficient to

avoid smoking-related health problems for mother and child

- It is OK to resume smoking after birth

- Only new-borns or young children are susceptible to the harms of ETS

- Smoking is $\mathrm{OK}$ in the car if children are not present (Gould et al. 2013c, 2015c)

4. Dangers of quitting and treatment (Gould et al. 2013c, 2015c)

- Quitting can bring on cancer or other serious illnesses

- NRT could make you want to smoke more, and NRT is harmful for the baby
Suggested response or strategy

Improve educational messages for pregnancy and explain causality. Effects of smoking on the foetus need to be made more tangible in a culturally appropriate manner. The connection between low birthweight and later obesity, type 2 diabetes and heart disease needs to be promoted. Portray Indigenous people in educational materials.

Emphasise the benefits of cessation for mother and baby and address relative influences of smoking and ETS. These messages address response efficacy; that is, cessation is worthwhile and effective.

Educate smokers on stress-inducing withdrawal effects and treatment. Assess individuals for anxiety and depression; provide supportive counselling and treatment for underlying anxiety and depression. Promote cessation as a means of becoming less stressed in the long term. Educate health professionals on how to approach these topics and prescribe appropriate pharmacotherapy for use in pregnancy, such as NRT to reduce withdrawal effects.

Educational messages. Pre-empt this topic in smokers and non-smokers who are prediabetic or diabetic, and first-time mothers who may be nervous about birth.

Encourage cessation over reduced consumption (unless using NRT). Explain about compensatory smoking. A hand-held CO meter may assist in monitoring compensatory smoking and motivating quit attempts.

Emphasise the benefits of staying smoke-free for the mother herself and the child. Build efficacy for abstinence.

Educational messages emphasising that the ETS risks are high for all children (and everyone else including pregnant non-smoking mothers); make the effects more tangible.

Educate on the concept of third-hand smoke particles and promote total smoke-free environments.

Explain the timeframe of cancer induction; that is, cancer can have been induced many years before it is diagnosed and that quitting does not bring on cancer-it is always better to stop smoking.

Address individual concerns about NRT and explain how NRT works. Provide enough knowledge so Indigenous women can make an informed decision about taking NRT and can compare the risks to continued smoking. 
fast-acting oral form (Brose et al. 2013; Chamberlain et al. 2013; Coleman et al. 2015). NRT is considered safe to use for the pregnant mother and foetus, according to the latest Cochrane review (Coleman et al. 2015). Counselling in pregnancy produces a modest 4-6\% increased quit rate compared with no counselling (Chamberlain et al. 2013). Adding NRT to counselling can triple the effectiveness of counselling alone (Pollak et al. 2007).

In a randomised controlled trial in a clinical setting, nicotine patches were efficacious at 4 weeks compared with placebo (21.3 v. 11.7\%), but adherence was problematic after this time point (Coleman et al. 2012). In a large nonrandomised clinical sample (3500 participants), transdermal NRT combined with an oral form doubled the quit rate compared with no medication or monotherapy $(\mathrm{OR}=1.93)$ (Brose et al. 2013). The accelerated nicotine metabolism in pregnancy gives a physiological basis for higher doses being required (Dempsey et al. 2002). Even short periods of abstinence are beneficial for foetal growth.

Cutting down, as a harm reduction or quitting strategy, in pregnancy is reported in other populations (Graham et al. 2014). Owing to the risk of compensatory smoking, health gains are only realised if cutting down is accompanied with NRT. Preliminary studies involving pregnant smokers suggest that using NRT while cutting down is safe (Berlin et al. 2014), although pre-cessation use has not been addressed in formal guidelines (Zwar et al. 2014).

Counselling and pharmacotherapy are effective in Indigenous smokers generally (relative risk, RR 1.43; 95\% CI 1.03-1.98) (Carson et al. 2012a); however, it is unclear what approaches are effective for Indigenous women in pregnancy (Passey et al. 2013). Indigenous pregnant women sometimes interpret the discomfort they experience from 'cutting down' or quitting as psychological stress, and are unaware that these symptoms could be nicotine withdrawal, so educational approaches may be required (Passey et al. 2012a; Gould et al. 2013c). Similar considerations are seen in other vulnerable populations. Pre-cessation NRT may provide a bridge between cutting down and complete cessation, possibly assisting to ameliorate stress-inducing symptoms and increasing physical and psychological capabilities. However, it is not known how acceptable NRT is to Indigenous pregnant smokers (Gould et al. 2013b, 2013c). Educational and social marketing approaches could promote the use of NRT, increase client understanding about why NRT is safer than smoking in pregnancy and how it works (Gould et al. 2015a).

Translational strategies relate to service provision on the outer ring of the $\mathrm{BCW}$ and are recommended in primary care. Clinician training and enabling providers to offer evidencebased therapies can achieve these approaches. Intentions to change smoking behaviour need to become a reality by health professionals giving practical assistance to enable and empower pregnant women to quit smoking. Best practice includes a range of behaviour change techniques addressing the psychosocial issues that Indigenous women encounter. Enhancing self-efficacy may lead to more quit attempts, but these attempts also need to be of a 'better quality' in order to give people the best chances to successfully quit. In the general population, it has been shown that providing practical assistance, such as offering NRT, has a significant influence on cessation outcomes (Aveyard et al. 2012).

\section{Systemic barriers to accessing evidence-based cessation methods and how they can be addressed}

Several studies draw attention to the barriers for Indigenous pregnant smokers to receiving evidence-based therapies (Passey et al. 2012b; Gould et al. 2013b; Passey et al. 2013; Gould 2014). Barriers that are largely remediable and should be targeted strenuously include lack of knowledge and expertise by clinicians, lack of access to culturally appropriate programs and lack of access to subsidised oral and combination forms of NRT for pregnant women. These barriers impinge on individuals' capacity, opportunity and motivation to change, as indicated by the three central segments of the BCW. In NSW, a targeted Quit For New Life program uses a translational approach by providing a family-orientated program, cessation support for Indigenous pregnant mothers and free oral forms of NRT (currently under evaluation).

\section{Clinician barriers}

Clinicians commonly have concerns about prescribing NRT for pregnant women, and may miss opportunities to intervene. UK general practitioners (GPs) reported safety concerns and low confidence in prescribing NRT, despite the majority agreeing that NRT was safer than smoking when pregnant (Herbert et al. 2005). In Australia, knowledge of cessation strategies is poor among Australian antenatal health providers caring for Indigenous women (Passey et al. 2012b). Some health workers considered it not worthwhile to offer cessation advice to Indigenous pregnant women due to low perceived success (Passey et al. 2012b). Preliminary findings from Australian GPs working in Indigenous health show a similar lack of optimism and inadequate follow up (Gould et al. 2015e). A study of Indigenous smokers of reproductive age showed that $40 \%$ of smokers, who had consulted their health provider about quitting, rated the assistance they received as poor, thus limiting their physical opportunity and capacity for change (Gould et al. 2015c). Researchers conclude that the support offered to Indigenous women has hitherto been insufficient, and $38 \%$ are offered no assistance (Passey and Sanson-Fisher 2015).

Improving the skills of ante-natal and primary care providers for smoking cessation, through training and incentivisation, has the potential to improve Indigenous health and cessation outcomes (Carson et al. 2012b; Passey et al. 2013; Passey and Sanson-Fisher 2015). GPs and multidisciplinary teams have opportunities to engage with Indigenous women when confirming pregnancy, and often provide shared antenatal care for rural and remote Indigenous women.

\section{New guidelines}

The recently updated Royal Australian College of General Practitioners (RACGP) guidelines include combination NRT if required in pregnancy (Zwar et al. 2014). The management of smoking cessation in Indigenous pregnant women can be complex. Concern about the lack of knowledge of effective cessation approaches specific to Indigenous pregnant women led 
to the recent publication of interim pragmatic guidelines (Gould et al. 2015a, 2015b). This approach is aimed at primary healthcare professionals. These guidelines, based on an ABCD mnemonic (Ask, Brief advice, Cessation support, Discuss the psychosocial context), encourage a proactive translational approach. The ABCD approach includes culturally competent behavioural counselling using the 'teachable moment' of pregnancy (McBride et al. 2003), a visual aid to educate on the issue of stress and withdrawal symptoms, a quit plan to engage the client in goal setting and problem-solving, and an algorithm to guide the expedited use of NRT including combination forms if required (Gould et al. 2015a).

\section{Lack of subsidies}

A significant barrier to capability and opportunity for smoking cessation in pregnant women, and hampering the service provision by providers, is the lack of subsidy for oral or combination NRT on Australia's Pharmaceutical Benefits Scheme (PBS). The Australian Association of Smoking Cessation Professionals has lobbied for 3 years to correct this inequity. Access would be facilitated, should the PBS agree to extend the NRT listing. So far, pharmaceutical companies are reluctant to supply oral NRT to the PBS or apply for it to be listedan essential first step for putting in an application for listing extension. The Australian Government may need to consider alternatively funded supplies under a scheme tailored specifically to this vulnerable population.

The views of Indigenous women should be further explored to determine the most effective approaches. Such a study could determine what support and counselling techniques would be preferred, and who should deliver them; and also assess willingness to use evidence-based approaches, such as NRT in pregnancy.

Primary care approaches that could be strengthened include counselling using behaviour change techniques known to be effective in pregnancy, routine discussion of the psychosocial context for smoking, educational approaches to improve health promotion messages, appropriate use of NRT in pregnancy, culturally competent practices, and following up women throughout their term. These approaches can be improved by investing in training for GPs and other health professionals in primary care settings, who have contact with pregnant women from the earliest stages of their pregnancies and routinely consult them in their reproductive years. Training could up-skill providers in culturally competent approaches, aid the translation of evidence into action and promote the uptake of evidencebased guidelines.

\section{Conclusion}

Pregnancy is both a risk for persistent smoking and an opportunity for behaviour change in Indigenous Australian women. Indigenous women, however, face intrinsic and extrinsic barriers in accessing evidence-based cessation therapy during pregnancy, including the lack of suitable services and access to NRT, and few culturally appropriate programs. Areas for immediate action have been outlined to refine anti-tobacco messages and provide cessation support, with reference to the $\mathrm{BCW}$. These approaches have potential to hasten the reduction in prevalence of smoking among Indigenous pregnant women, and aid in achieving state and national Indigenous health goals.

\section{Conflicts of interest}

No conflicts of interest to declare.

\section{References}

Australian Bureau of Statistics (2014) 4727.0.55.006 - Australian Aboriginal and Torres Strait Islander health survey: updated results, 2012-13. (Australian Bureau of Statistics: Canberra)

Australian Government (2011) Indigenous anti-smoking campaign: break the chain - quantitative Campaign effectiveness: research - executive summary. Available at http://www.quitnow.gov.au/internet/quitnow/ publishing.nsf/Content/btc-indsurvey-execsumm [Verified 15 November 2014]

Australian Government (2012) National tobacco campaign: more targeted approach- 2012-2013. Available at http://quitnow.gov.au/internet/ quitnow/publishing.nsf/Content/mta [Verified 7 July 2016]

Aveyard P, Begh R, Parsons A, West R (2012) Brief opportunistic smoking cessation interventions: a systematic review and meta-analysis to compare advice to quit and offer of assistance. Addiction 107(6), 1066-1073. doi:10.1111/j.1360-0443.2011.03770.x

Berlin I, Grange G, Jacob N, Tanguy ML (2014) Nicotine patches in pregnant smokers: randomised, placebo controlled, multicentre trial of efficacy. British Medical Journal 348, g1622. doi:10.1136/bmj.g1622

Brose LS, McEwen A, West R (2013) Association between nicotine replacement therapy use in pregnancy and smoking cessation. Drug and Alcohol Dependence 132(3), 660-664. doi:10.1016/j.drugalcdep.2013. 04.017

Cancer Council Queensland (2014) Shock over Indigenous pregnancy smoking rates. Available at http://www.cancerqld.org.au/page/news/ newsroom_2014/shock_over_indigenous_pregnancy_smoking_rates/ [Verified 28 December 2014]

Carson KV, Brinn MP, Peters M, Veale A, Esterman AJ, Smith BJ (2012a) Interventions for smoking cessation in Indigenous populations. Cochrane Database of Systematic Reviews 2012(1), CD009046.

Carson KV, Verbiest MEA, Crone MR, Brinn MP, Esterman AJ, Assendelft WJ, Smith BJ (2012b) Training health professionals in smoking cessation. Cochrane Database of Systematic Reviews 2012(5), CD000214.

Chamberlain C, O'Mara-Eves A, Oliver S, Caird JR, Perlen SM, Eades SJ, Thomas J (2013) Psychosocial interventions for supporting women to stop smoking in pregnancy. Cochrane Database of Systematic Reviews 2013(10), CD001055.

Coleman T, Cooper S, Thornton JG, Grainge MJ, Watts K, Britton J, Lewis S Smoking, Nicotine and Pregnancy (SNAP) Trial Team (2012) A Randomized trial of nicotine-replacement therapy patches in pregnancy. The New England Journal of Medicine 366(9), 808-818. doi:10.1056/ NEJMoa1 109582

Coleman T, Chamberlain C, Davey MA, Cooper SE, Leonardi-Bee J (2015) Pharmacological interventions for promoting smoking cessation during pregnancy. Cochrane Database of Systematic Reviews 2015(12), CD010078.

Dempsey D, Jacob P, Benowitz NL (2002) Accelerated metabolism of nicotine and cotinine in pregnant smokers. The Journal of Pharmacology and Experimental Therapeutics 301(2), 594-598. doi:10.1124/jpet. 301.2.594

Gould GS (2014) Exploring the barriers and enablers to smoking cessation in pregnant Aboriginal and Torres Strait Islander women with the behaviour change wheel. Australasian Epidemiologist 21(2), 31-35.

Gould GS, McEwen A, Watters T, Clough AR, van der Zwan R (2013a) Should anti-tobacco media messages be culturally targeted for 
Indigenous populations? A systematic review and narrative synthesis. Tobacco Control 22(4), e7. doi:10.1136/tobaccocontrol-2012-050436

Gould GS, Munn J, Watters T, McEwen A, Clough AR (2013b) Knowledge and views about maternal tobacco smoking and barriers for cessation in Aboriginal and Torres Strait Islanders: a systematic review and meta-ethnography. Nicotine \& Tobacco Research 15(5), 863-874. doi:10.1093/ntr/nts211

Gould GS, Munn J, Avuri S, Hoff S, Cadet-James Y, McEwen A, Clough AR (2013c) 'Nobody smokes in the house if there's a new baby in it': Aboriginal perspectives on tobacco smoking in pregnancy and in the household in regional NSW Australia. Women and Birth; Journal of the Australian College of Midwives 26(4), 246-253. doi:10.1016/j.wombi. 2013.08.006

Gould GS, Watt K, Stevenson L, McEwen A, Cadet-James Y, Clough AR (2014) Developing anti-tobacco messages for Australian Aboriginal and Torres Strait Islander peoples: evidence from a national crosssectional survey. BMC Public Health 14(1), 250. doi:10.1186/1471-2458$14-250$

Gould GS, Bittoun R, Clarke MJ (2015a) A pragmatic guide for smoking cessation counselling and the initiation of nicotine replacement therapy for pregnant Aboriginal and Torres Strait Islander smokers. Journal of Smoking Cessation 10, 96-106. doi:10.1017/jsc.2014.3

Gould GS, Bittoun R, Clarke M (2015b) Guidance for culturally competent approaches to smoking cessation for Aboriginal and Torres Strait Islander pregnant women - letter to the Editor. Nicotine \& Tobacco Research 18, 104-105.

Gould GS, Watt K, McEwen A, Cadet-James Y, Clough AR (2015c) Predictors of intentions to quit smoking in Aboriginal tobacco smokers of reproductive age in regional New South Wales (NSW), Australia: quantitative and qualitative findings of a cross-sectional survey. $B M J$ Open 5, e007020. doi:10.1136/bmjopen-2014-007020

Gould GS, Watt K, Cadet-James Y, Clough AR (2015d) Using the risk behaviour diagnosis scale to understand Australian Aboriginal smoking - a cross-sectional validation survey in regional New South Wales. Preventive Medicine Reports 2, 4-9. doi:10.1016/j.pmedr.2014. 10.004

Gould GS, Bonevski B, Watt K, Clarke M, Atkins L, Cadet-James Y (2015e) How are Australian general practitioners assisting pregnant women to quit? In 'Oceania Tobacco Control Conference', 20-22 October 2015, Perth, WA. p. 38. (Cancer Council WA)

Graham H, Flemming K, Fox D, Heirs M, Sowden A (2014) Cutting down: insights from qualitative studies of smoking in pregnancy. Health \& Social Care in the Community 22(3), 259-267. doi:10.1111/ hsc. 12080

Herbert R, Coleman T, Britton J (2005) UK general practitioners' beliefs, attitudes, and reported prescribing of nicotine replacement therapy in pregnancy. Nicotine \& Tobacco Research 7(4), 541-546. doi:10.1080/ 14622200500186015

Li Z, Zeki R, Hilder L, Sullivan EA (2012). Australia's mothers and babies 2010. (Australian Institute of Health and Welfare (AIHW) National Perinatal Epidemiology and Statistics Unit: Canberra)

Market Equity (2000). The forgotten smokers. Indigenous smoking: issues and responses. (Australian Medical Association and Australian Pharmaceutical Manufacturers Association)

McBride CM, Emmons KM, Lipkus IM (2003) Understanding the potential of teachable moments: the case of smoking cessation. Health Education Research 18(2), 156-170. doi:10.1093/her/18.2.156

Michie S, van Stralen MM, West R (2011) The behaviour change wheel: a new method for characterising and designing behaviour change interventions. Implementation Science 6(42), 1-11.
Murphy M, Mee V (1999) Australia's National Tobacco Campaign: evaluation report, volume 1 . Chapter 6 . The impact of the National Tobacco Campaign on Indigenous communities. (Department of Health and Ageing: Canberra)

Naughton F, Eborall H, Sutton S (2013) Dissonance and disengagement in pregnant smokers: a qualitative study. Journal of Smoking Cessation 8, 24-32. doi:10.1017/jsc.2013.4

Nicholson AK, Borland R, Sarin J, Wallace S, van der Sterren AE, Stevens M, Thomas DP (2015a) Recall of anti-tobacco advertising and information, warning labels and news stories in a national sample of Aboriginal and Torres Strait Islander smokers. The Medical Journal of Australia 202(10), 67-72. doi:10.5694/mja14.01628

Nicholson AK, Borland R, Davey ME, Stevens M, Thomas DP (2015b) Predictors of wanting to quit in a national sample of Aboriginal and Torres Strait Islander smokers. The Medical Journal of Australia 202(10), 26-32. doi:10.5694/mja15.00199

NSW Department of Health (2014) NSW Tobacco Snapshot - May 2014. Available at http://www.health.nsw.gov.au/tobacco/pages/default.aspx [Verified 27 September 2014]

Passey M, Sanson-Fisher RW (2015) Provision of antenatal smoking cessation support: a survey with pregnant Aboriginal and Torres Strait Islander women. Nicotine \& Tobacco Research 17, 746-749. doi:10.1093/ntr/ntv019

Passey M, Gale J, Sanson-Fisher R (2011) 'It's almost expected': rural Australian Aboriginal women's reflections on smoking initiation and maintenance: a qualitative study. BMC Women's Health 11(55), 1-12.

Passey M, D'Este CA, Stirling JM, Sanson-Fisher RW (2012a) Factors associated with antenatal smoking among Aboriginal and Torres Strait Islander women in two jurisdictions. Drug and Alcohol Review 31(5), 608-616. doi:10.1111/j.1465-3362.2012.00448.x

Passey M, D'Este CA, Sanson-Fisher R (2012b) Knowledge, attitudes and other factors associated with assessment of tobacco smoking among pregnant Aboriginal women by health care providers: a cross-sectional survey. BMC Public Health 12, 165. doi:10.1186/1471-2458-12-165

Passey ME, Bryant J, Hall AE, Sanson-Fisher RW (2013) How will we close in smoking rates for pregnant Indigenous women. The Medical Journal of Australia 199(1), 39-41. doi:10.5694/mja12.11848

Pollak KI, Oncken CA, Lipkus IM, Lyna P, Swamy GK, Pletsch PK, Peterson BL, Heine RP, Brouwer RJ, Fish L, Myers ER (2007) Nicotine replacement and behavioral therapy for smoking cessation in pregnancy. American Journal of Preventive Medicine 33(4), 297-305. doi:10.1016/ j.amepre.2007.05.006

Thomas D (2012) National trends in Aboriginal and Torres Strait Islander smoking and quitting, 1994-2008. Australian and New Zealand Journal of Public Health 36(1), 24-29. doi:10.1111/j.1753-6405.2011. 00817.x

Walker N, Johnston V, Glover M, Bullen C, Trenholme A, Chang A, Morris P, Segan C, Brown N, Fenton D, Hawthorne E, Borland R, Parag V, Von Blaramberg T, Westphal D, Thomas D (2015) Effect of a familycentered, secondhand smoke intervention to reduce respiratory illness in Indigenous infants in Australia and New Zealand: a randomized controlled trial. Nicotine \& Tobacco Research 17(1), 48-57. doi:10.1093/ ntr/ntu128

Zwar N, Richmond R, Borland R, Peters M, Litt J, Bell J, Caldwell B, Ferretter I (2014) Supporting smoking cessation: a guide for health professionals. (The Royal Australian College of General Practitioners: Melbourne) Available at http://www.racgp.org.au/your-practice/guide lines/smoking-cessation/ [Verified 15 June 2016] 